\title{
Kernos
}

Revue internationale et pluridisciplinaire de religion grecque antique

4| 1991

Varia

\section{P. Somville, Études grecques}

\section{Vinciane Pirenne-Delforge}

URL : http://journals.openedition.org/kernos/517

DOI : 10.4000/kernos.517

ISSN : 2034-7871

\section{Éditeur}

Centre international d'étude de la religion grecque antique

\section{Édition imprimée}

Date de publication : 1 janvier 1991

Pagination : 347

ISSN : 0776-3824

\section{Référence électronique}

Vinciane Pirenne-Delforge, «P. Somville, Études grecques », Kernos [En ligne], 4| 1991, mis en ligne le 06 avril 2011, consulté le 21 septembre 2020. URL : http://journals.openedition.org/kernos/517 ; DOI : https://doi.org/10.4000/kernos.517 
séduira tout autant par l'aisance de son auteur à dessiner une telle fresque de l'imaginaire des Grecs. On souscrira volontiers au propos d'ensemble qui consiste à poser la féminité en repoussoir des qualités proprement masculines, avec toutes les interactions que cela implique entre les deux domaines. Mais certaines analyses sont d'une grande complexité, et leur raffinement est tel parfois que l'ingéniosité semble avoir pris le pas sur la rigueur.

Vinciane PIRENNE-DELFORGE (Liège)

Pierre SOMVILLE, Études grecques, Liège, Pierre Mardaga Éd., 1990, 1 vol., 172 p., 8 pl.

Ce livre est, au dire de l'A. lui-même, un "voyage zigzaguant à travers la mosaïque colorée ou le damier noir-et-blanc d'une Grèce à l'éternelle jeunesse». Reprenant ici diverses contributions publiées précédemment dans des revues spécialisées, Pierre Somville offre un véritable poème sur une civilisation toujours porteuse de sens à travers les siècles, jusque dans la plus infime de ses manifestations. Que ce soit dans l'analyse du motif du plongeon, du dauphin, dans l'étude des jeux de mots significatifs, et à travers tant d'autres essais de comparaison littéraire et iconographique, le lecteur ne peut que succomber au charme de cette sensibilité intuitive, qui ne craint pas de maltraiter la chronologie parfois.

Vinciane PIRENNE-DELFORGE (Liège) 